\title{
Gradients in Wealth Quintile and Access to Maternal Care Services: Reanalysis of Data from the Philippines National Demographic and Health Survey 2013
}

\author{
Carl Abelardo T. Antonio
}

Department of Health Policy and Administration, College of Public Health, University of the Philippines Manila

\begin{abstract}
Objective. To quantify the magnitude of difference in access to selected maternal care services among Filipino women who belong to different income groups.

Methods. Point and interval estimates of the inter-quintile difference in access to a selected maternal care services (family planning; antenatal care; facility-based delivery; skilled birth attendance; and postnatal care) were constructed using weighed coverage data from the Philippines National Demographic and Household Survey 2013.

Results. There is a generally increasing trend in inter-quintile differences in coverage from the lowest to the highest income quintile group (Q1-Q4 > Q1-Q3 > Q1-Q5 > Q1-Q2 > Q2-Q5 > Q2Q4 > Q3-Q5 > Q3-Q4 > Q2-Q4 > Q4-Q5). Differences in maternal care access between wealth groups ranged from less than $1 \%$ for antenatal care $\left(\mathrm{D}_{\mathrm{O} 2-03}-0.4 \%[95 \% \mathrm{Cl}-1.9 \%\right.$ to $\left.1.1 \%]\right)$ to as much as $60 \%$ for facility-based delivery $\left(D_{01-05}-58.4 \%[95 \% \mathrm{Cl}-61.2 \%\right.$ to $-55.6 \%]$ ). Such differences persist even between the two highest quintiles (facility based delivery $D_{Q 4-05}-9.7 \%[95 \% \mathrm{Cl}-$ $12.5 \%$ to $-6.9 \%]$ ).
\end{abstract}

Conclusion. Gradients in access to selected maternal care services exist among Filipino women who belong to different wealth quintiles. The call for stakeholders, therefore, is to intensify efforts to narrow such gaps because, within and across communities, we affirm that no women "should die in the course of the normal process of reproduction" and no families must suffer the devastating consequences of such an occurrence.

Key Words: healthcare disparities, maternal health services, Philippines

\section{Introduction}

The burden of maternal deaths in the Philippines, a developing, lower-middle-income economy ${ }^{1}$ in the Western

Corresponding author: Carl Abelardo T. Antonio, MPH, MD, FRSPH, AFCHSM

Department of Health Policy and Administration

College of Public Health

University of the Philippines Manila

625 Pedro Gil St., Ermita, Manila 1000 Philippines

Telephone: +6323428932

Fax number: +632 5232997

Email: ctantonio@up.edu.ph
Pacific, ${ }^{2}$ precludes the country from attaining the global ${ }^{3}$ and national ${ }^{4}$ goals of improving the status of maternal health. International estimates place the country's maternal mortality ratio at around 120 per 100,000 live births in $2013,{ }^{5}$ while local authorities reported a higher figure of 221 per 100,000 live births in 2011, ${ }^{6}$ both of which are not far from their 1990 levels. In response, stakeholders have identified essential clinical and public health interventions at the community and health facility levels to ensure early recognition and facilitate prompt treatment of preventable causes of maternal ill-health across the continuum of maternal care and thereby avert unnecessary maternal deaths. ${ }^{7,8}$

Availability of resources and packages of essential interventions, however, do not necessarily translate to actual receipt of necessary care when and where it is needed. Disparities or inequities in healthcare access and, ultimately, health status, across different groups of individuals are wellknown., ${ }^{9,11}$ In maternal health, the Three Delays Model posits that socioeconomic and cultural factors, accessibility of facilities, and quality of care result to decisions, at both the provider and client sides, that delay the receipt by women of appropriate care during pregnancy, delivery and the postnatal period. ${ }^{12}$ Measurement of disparities in access to maternal health services have been carried out in several settings, ${ }^{13,14,15}$ but literature in and about the Philippines is, to the author's knowledge, sparse. Information on health inequities becomes more resonant as the country moves towards attainment of universal health care. ${ }^{16}$ Thus, the current research was carried out to fill this gap in knowledge.

This paper aims to quantify the magnitude of difference in access to selected maternal care services among Filipino women who belong to different income groups.

\section{Materials and Methods}

\section{Data source}

Weighed proportions of reported access to selected maternal care services, stratified by wealth quintile, were obtained from the final report of the Philippines National Demographic and Health Survey (NDHS) 2013. ${ }^{17}$ The selected services represent the minimum package of services recommended by international and local bodies across the continuum of maternal care (pre-pregnancy, 
during pregnancy and delivery, and after delivery) (Table 1). ${ }^{7,8}$ Data was encoded in Microsoft ${ }^{\circledR}$ Office Excel ${ }^{\circledR} 2007$ (12.0.6718.5000) SP3 MSO (12.0.6718.5000) for processing and analysis.

\section{Data analysis}

The point estimates of the inter-quintile difference in access to a particular maternal care service were computed as the difference between the reported coverage for a higher quintile $\left(p_{2}\right)$ from the coverage for a lower quintile $\left(p_{1}\right)$ :

\section{Point Estimate of Interquintile Difference $(D)=p_{1}-p_{2}$}

Interval estimates at the $95 \%$ confidence level for each inter-quintile difference for a particular maternal care service were constructed from the pooled standard error for the difference between two proportions $\left(n_{1}\right.$ represent the sample size of the lower quintile, while $n_{2}$ represent the sample size for the higher quintile):

$$
\text { Interval Estimate }=D \pm 1.96 \sqrt{\frac{p_{1}\left(1-p_{1}\right)}{n_{1}}+\frac{p_{2}\left(1-p_{2}\right)}{n_{2}}}
$$

Thus, negative values for both point and interval estimates of inter-quintile differences indicate that the level of reported coverage for a particular maternal care service is greater for the higher compared to the lower quintile group (i.e., $p_{1}<p_{2}$ ), while positive values indicate the opposite (i.e., $p_{1}>p_{2}$ ).

Analysis was supplemented through generation of simple tables and graphs using Microsoft ${ }^{\circledR}$ Office Excel ${ }^{\circledR}$ 2007 (12.0.6718.5000) SP3 MSO (12.0.6718.5000).

Comparison was carried out in three phases: a) across all quintiles and across all identified maternal care services (10 comparison groups for all five services); b) between adjacent quintiles for all identified maternal care services (four comparison groups for all five services); and c) across all quintiles for each specific maternal care service (10 comparison groups for each of the five services).

\section{Results}

Data of a nationally representative sample of women from at least 2,697 (women with a live birth in the two years preceding the survey) to at most 9,729 (currently married women age 15-49) respondents were derived from the NDHS report. The distribution of respondents by wealth quintile for each sample population is shown in Table 2.

Table 1. Selected indicators, classified across the continuum of maternal care, reported in the Philippines National Demographic and Household Survey 2013

\begin{tabular}{|c|c|c|}
\hline Phase & Service & NDHS Indicator \\
\hline Pre-pregnancy & Family planning & $\begin{array}{l}\text { Proportion of currently married women age 15-49 currently using any modern method of contraception. Modern } \\
\text { methods of contraception include permanent methods (bilateral tubal ligation and vasectomy), artificial methods } \\
\text { (intrauterine devices, oral pills, injectables and implants), and natural methods (cervical mucus method, basal body } \\
\text { temperature, symptothermal method, standard days method, and lactational amenorrhea method. }\end{array}$ \\
\hline Pregnancy & Antenatal care & $\begin{array}{l}\text { Proportion of women age } 15-49 \text { who had a live birth in the preceding five years who received antenatal care from a } \\
\text { skilled professional (i.e., physician, nurse or midwife) }\end{array}$ \\
\hline \multirow{2}{*}{ Delivery } & $\begin{array}{l}\text { Facility-based } \\
\text { delivery }\end{array}$ & Proportion of live births in the preceding five years delivered in a health facility \\
\hline & $\begin{array}{l}\text { Skilled birth } \\
\text { attendance }\end{array}$ & Proportion of live births in the preceding five years delivered by a skilled provider (i.e., physician, nurse or midwife) \\
\hline Post-delivery & Postnatal care & $\begin{array}{l}\text { Proportion of women age } 15-49 \text { giving birth in the preceding two years who received a postnatal check-up in the first } \\
\text { two days after giving birth }\end{array}$ \\
\hline
\end{tabular}

Table 2. Distribution of women respondents to the NDHS, by maternal care service and wealth quintile, Philippines 2013

\begin{tabular}{|c|c|c|c|c|c|c|}
\hline \multirow{2}{*}{$\begin{array}{l}\text { Sample Population } \\
\text { (Maternal care service) }\end{array}$} & \multicolumn{6}{|c|}{ Respondents } \\
\hline & $\begin{array}{c}\text { Quintile } 1 \\
\text { (Lowest) }\end{array}$ & Quintile 2 & Quintile 3 & Quintile 4 & $\begin{array}{l}\text { Quintile } 5 \\
\text { (Highest) }\end{array}$ & Total \\
\hline \multirow{2}{*}{$\begin{array}{l}\text { Currently married women age } 15-49 \\
\text { (Use of contraception) }\end{array}$} & 1,945 & 1,919 & 1,996 & 2,012 & 1,857 & 9,729 \\
\hline & $20.0 \%$ & $19.7 \%$ & $20.5 \%$ & $20.7 \%$ & $19.1 \%$ & $100.0 \%$ \\
\hline \multirow{2}{*}{$\begin{array}{l}\text { Women age } 15-49 \text { who had a live birth in the preceding five } \\
\text { years (Antenatal care) }\end{array}$} & 1,277 & 1,098 & 1,062 & 962 & 789 & 5,188 \\
\hline & $24.6 \%$ & $21.2 \%$ & $20.5 \%$ & $18.5 \%$ & $15.2 \%$ & $100.0 \%$ \\
\hline \multirow{2}{*}{$\begin{array}{l}\text { Live births in the preceding five years } \\
\text { (Facility-based delivery and skilled birth attendance) }\end{array}$} & 1,916 & 1,525 & 1,395 & 1,214 & 932 & 6,982 \\
\hline & $27.4 \%$ & $21.8 \%$ & $20.0 \%$ & $17.4 \%$ & $13.3 \%$ & $100.0 \%$ \\
\hline \multirow{2}{*}{$\begin{array}{l}\text { Women age } 15-49 \text { giving birth in the preceding two years } \\
\text { (Postnatal care) }\end{array}$} & 686 & 585 & 587 & 480 & 359 & 2,697 \\
\hline & $25.4 \%$ & $21.7 \%$ & $21.8 \%$ & $17.8 \%$ & $13.3 \%$ & $100.0 \%$ \\
\hline
\end{tabular}


Table 3. Reported coverage for each maternal care service, by wealth quintile, Philippines 2013 (National Demographic and Health Survey)

\begin{tabular}{|c|c|c|c|c|c|c|}
\hline \multirow[b]{2}{*}{ Indicator } & \multicolumn{6}{|c|}{ Coverage (\%) } \\
\hline & $\begin{array}{l}\text { Quintile } 1 \\
\text { (Lowest) }\end{array}$ & Quintile 2 & Quintile 3 & Quintile 4 & $\begin{array}{l}\text { Quintile } 5 \\
\text { (Highest) }\end{array}$ & Total \\
\hline $\begin{array}{l}\text { Proportion of currently married women age } 15-49 \text { currently } \\
\text { using any modern method of contraception }\end{array}$ & 33.0 & 40.3 & 41.4 & 39.1 & 34.0 & 37.6 \\
\hline $\begin{array}{l}\text { Proportion of women age } 15-49 \text { who had a live birth in the } \\
\text { preceding five years who received antenatal care from a } \\
\text { skilled professional }\end{array}$ & 88.5 & 96.3 & 96.7 & 99.4 & 98.6 & 95.4 \\
\hline $\begin{array}{l}\text { Proportion of live births in the preceding five years delivered } \\
\text { in a health facility }\end{array}$ & 32.8 & 55.0 & 69.0 & 81.5 & 91.2 & 61.1 \\
\hline $\begin{array}{l}\text { Proportion of live births in the preceding five years delivered } \\
\text { by a skilled provider }\end{array}$ & 42.2 & 71.0 & 83.8 & 92.4 & 96.2 & 72.8 \\
\hline $\begin{array}{l}\text { Proportion of women age } 15-49 \text { giving birth in the preceding } \\
\text { two years who received a postnatal check-up in the first two } \\
\text { days after giving birth }\end{array}$ & 46.4 & 69.3 & 80.1 & 86.8 & 92.0 & 72.0 \\
\hline
\end{tabular}

Table 4. Distribution of women respondents to the NDHS, by maternal care service and wealth quintile, Philippines 2013

\begin{tabular}{|c|c|c|c|c|c|}
\hline \multirow{2}{*}{$\begin{array}{c}\text { Wealth } \\
\text { Quintile } \\
\text { Comparison }\end{array}$} & \multicolumn{5}{|c|}{ Rank } \\
\hline & $\begin{array}{l}\text { Use of any modern } \\
\text { method of contraception }\end{array}$ & $\begin{array}{l}\text { Antenatal care from a } \\
\text { skilled professional }\end{array}$ & $\begin{array}{l}\text { Live births delivered } \\
\text { in a health facility }\end{array}$ & $\begin{array}{l}\text { Live births delivered } \\
\text { by a skilled provider }\end{array}$ & $\begin{array}{l}\text { Postnatal check-up in the first } \\
\text { two days after giving birth }\end{array}$ \\
\hline Q1 - Q2 & 3 & 4 & 6 & 4 & 4 \\
\hline Q1 - Q3 & 1 & 3 & 3 & 3 & 3 \\
\hline $\mathrm{Q} 1-\mathrm{Q} 4$ & 5 & 1 & 2 & 2 & 2 \\
\hline Q1 - Q5 & 10 & 2 & 1 & 1 & 1 \\
\hline Q2 - Q3 & 9 & 10 & 8 & 7 & 8 \\
\hline $\mathrm{Q} 2$ - Q4 & 8 & 5 & 5 & 6 & 6 \\
\hline Q2 - Q5 & 4 & 7 & 4 & 5 & 5 \\
\hline Q3 - Q4 & 7 & 6 & 9 & 9 & 9 \\
\hline Q3 - Q5 & 2 & 8 & 7 & 8 & 7 \\
\hline Q4 - Q5 & 6 & 9 & 10 & 10 & 10 \\
\hline
\end{tabular}

General trend in inter-quintile differences: All inter-quintile comparisons (10 comparison groups)

A cursory examination of the data in Table 3 indicates that, in general, coverage for maternal care services increases with wealth quintile. The only exception to this trend is seen among currently married women age 15-49 years who reported use of a modern method of contraception, where the highest coverage is seen among those belonging to the third quintile.

This trend is further highlighted by the inter-quintile differences in coverage, with the magnitude of differences generally increasing as one moves from the lowest to the highest income quintile group as shown in Table 4. This trend can also be expressed as follows:

$$
\begin{gathered}
\mathrm{Q}_{1}-\mathrm{Q}_{4}>\mathrm{Q}_{1}-\mathrm{Q}_{3}>\mathrm{Q}_{1}-\mathrm{Q}_{5}>\mathrm{Q}_{1}-\mathrm{Q}_{2}>\mathrm{Q}_{2}-\mathrm{Q}_{5}>\mathrm{Q}_{2}-\mathrm{Q}_{4}>\mathrm{Q}_{3}-\mathrm{Q}_{5}> \\
\mathrm{Q}_{3}-\mathrm{Q}_{4}>\mathrm{Q}_{2}-\mathrm{Q}_{4}>\mathrm{Q}_{4}-\mathrm{Q}_{5}
\end{gathered}
$$

The highest inter-quintile difference was between the lowest and highest quintiles for facility-based delivery (DQ1Q5 $-58.4 \%$ [ $95 \%$ CI $-61.2 \%$ to $-55.6 \%]$ ), while the lowest was found for antenatal coverage between the second and third quintiles (DQ2-Q3 $-0.4 \%$ [95\% CI $-1.9 \%$ to $1.1 \%]$ ).
General trend in inter-quintile differences: Adjacent quintiles (four comparison groups)

There is a decreasing trend in differences in coverage for maternal care services between adjacent quintiles as the comparison moves from the lowest to the highest income quintile groups (i.e., $\mathrm{Q}_{1}-\mathrm{Q}_{2}>\mathrm{Q}_{2}-\mathrm{Q}_{3}=\mathrm{Q}_{3}-\mathrm{Q}_{4}>\mathrm{Q}_{4}-\mathrm{Q}_{5}$ ). For instance, the inter-quintile difference between the first and second quintiles is at most about a third higher than those between the fourth and highest quintiles (skilled attendance at birth DQ1-Q2 $-28.8 \%$ [95\% CI $-32.0 \%$ to $-25.6 \%$; facility based delivery DQ4-05 $-9.7 \%$ [95\% CI $-12.5 \%$ to $-6.9 \%]$ ).

Current use of any modern method of contraception

Women who belong to the lowest income quintile have lower reported use of any modern method of contraception ${ }^{a}$ when compared to higher wealth groups (Figure 1). The gap is highest between the first and third quintiles (DQ1-Q3 $-8.4 \%$ [95\% CI $-11.4 \%$ to $-5.4 \%]$ ), while there is an almost negligible

a For purposes of discussion, modern methods of contraception include permanent methods (bilateral tubal ligation and vasectomy), artificial methods (intrauterine devices, oral pills, injectables and implants), and natural methods (cervical mucus method, basal body temperature, symptothermal method, standard days method, and lactational amenorrhea method. ${ }^{17}$ 
difference between the first and fifth quintiles (DQ1-Q5 $-1.0 \%$ [ $95 \% \mathrm{CI}-4.0 \%$ to $2.0 \%]$ ]). On the other hand, the second to fourth income quintiles have a higher reported use of any modern method of contraception when compared to highest wealth group (DQ2-Q5 6.3\% [95\% CI 3.2\% to 9.4\%]; DQ3-Q5 7.4 [ $95 \%$ CI $4.3 \%$ to $10.5 \%$ ]; DQ4-Q5 $5.1 \%$ [ $95 \%$ CI $2.1 \%$ to $8.1 \%$ ]).

\section{Antenatal care from a skilled professional}

There is greater coverage among higher compared to lower wealth groups as indicated by the differences in reported receipt of antenatal care from a skilled provider ${ }^{b}$ (Figure 2), with the highest gap found among those who belong to the lowest income quintile (DQ1-Q2 -7.8\% [95\% CI 9.9\% to $-5.7 \%$ ]; DQ1-Q3 $-8.2 \%$ [95\% CI $-10.3 \%$ to $-6.1 \%$ ]; DQ1-Q4 $-10.9 \%$ [95\% CI $-12.7 \%$ to $-9.1 \%$ ]; DQ1-Q5 $-10.1 \%$ [95\% CI $12.0 \%$ to $-8.2 \%])$. The magnitude of differences between the higher quintile groups $\left(\mathrm{Q}_{2}\right.$ to $\left.\mathrm{Q}_{5}\right)$ is almost a third lower than those between the lowest and next higher income groups.

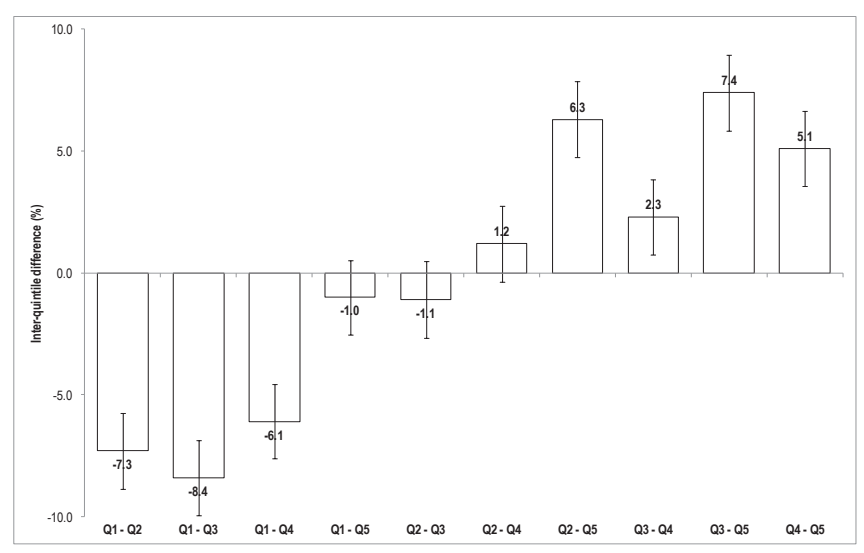

Figure 1. Inter-quintile differences in reported use of any modern method of contraception among currently married women aged 15-49 years, Philippines, 2013.

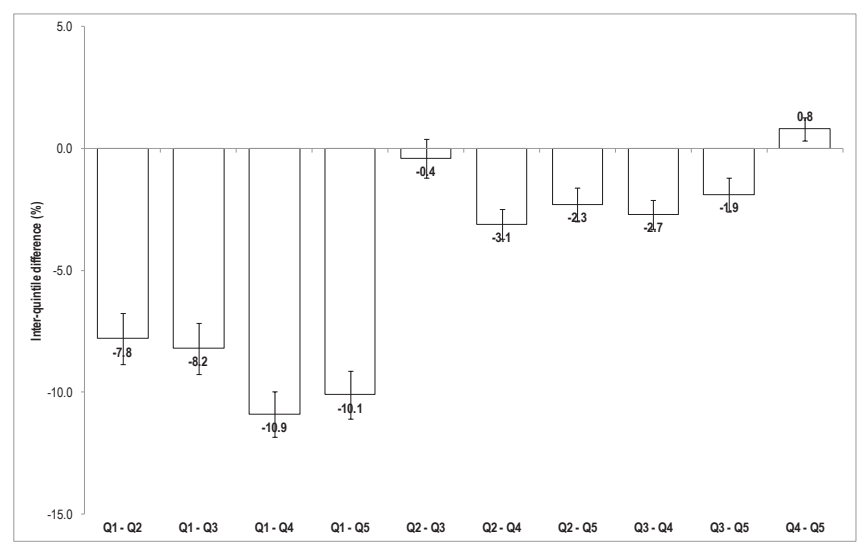

Figure 2. Inter-quintile differences in reported receipt of antenatal care form a skilled provider among women age 1549 years who had a live birth in the preceding five years, Philippines 2013.

${ }^{\mathrm{b}}$ Skilled providers of antenatal care include physicians, nurses and midwives. ${ }^{17}$

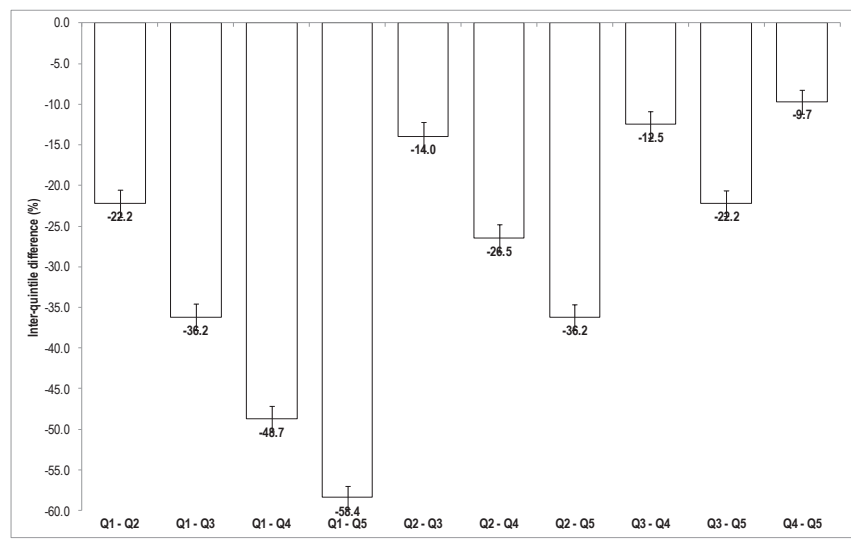

Figure 3. Inter-quintile differences in live births in the preceding five years reported as having been delivered in a health facility, Philippines 2013.

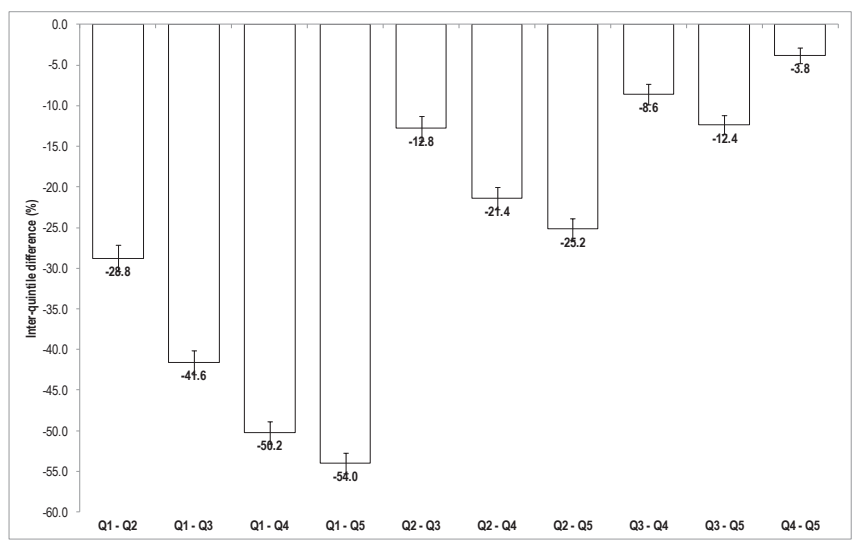

Figure 4. Inter-quintile differences in live births in the preceding five years reported as having been delivered by a skilled professional, Philippines 2013.

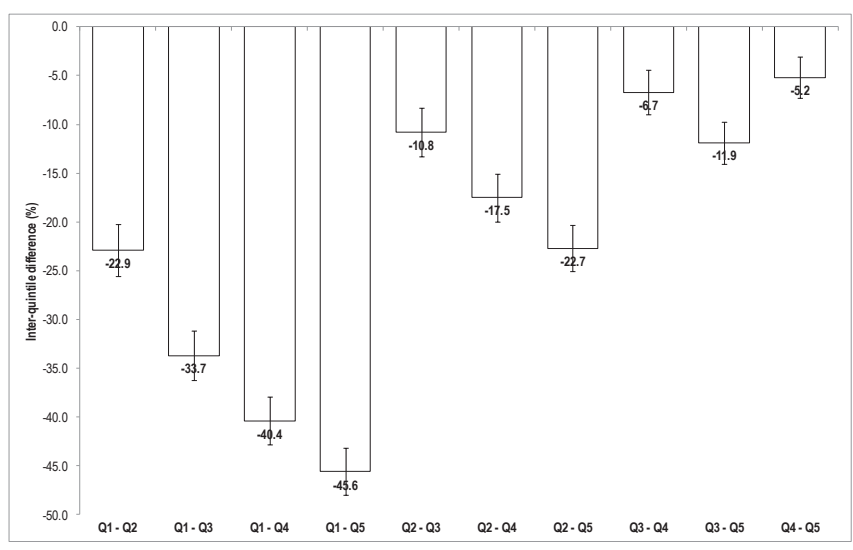

Figure 5. Inter-quintile differences in reported receipt of postnatal care among women with a live birth in the preceding two years, Philippines 2013.

\section{Facility-based delivery}

A consistent increasing trend in inter-quintile differences is notable with respect to delivery of a live birth in a health facility (Figure 3). The second income quintile, for 
instance, has a reported coverage about 20 percentage points higher than the lowest income quintile (DQ1-Q2 -22.2\% [95\% CI $-25.5 \%$ to $-18.9 \%]$ ). This difference more than doubles between the first and highest income quintiles (DQ1-Q5 $-58.4 \%$ [95\% CI $-61.2 \%$ to $-55.6 \%])$. The difference in coverage between the two highest quintiles indicate that about $10 \%$ more women who belong to the fifth income quintile delivery in a health facility compared to those who belong to the fourth income quintile (DQ4-Q5 -9.7\% [95\% CI - $12.5 \%$ to $6.9 \%])$.

\section{Skilled attendance at birth}

The trend in inter-quintile differences in skilled attendance at birthc (Figure 4) is almost the same for facilitybased delivery (DQ1-Q2 $-28.8 \%$ [95\% CI $-32.0 \%$ to $-25.6 \%$ ]; DQ1-Q5 $-54.0 \%$ [95\% CI $-56.5 \%$ to $-51.5 \%]$ ), although the differences in coverage between the higher quintiles is of a lower magnitude compared to those for facility-based delivery. For instance, the difference between the two highest quintiles is less than 5\% (DQ4-Q5 -3.8\% [95\% CI -5.7\% to $-1.9 \%]$ ).

\section{Postnatal care}

Receipt of postnatal care within two days after delivery is highest for the firth income quintile, resulting to a difference in coverage ranging from $5 \%$ to almost $50 \%$ when compared to lower income groups (DQ1-Q5 $-45.6 \%$ [95\% CI $50.3 \%$ to $-40.9 \%$ ]; DQ2-Q5 $-22.7 \%$ [95\% CI $-27.4 \%$ to $-18.0 \%$ ]; DQ3-Q5 - $11.9 \%$ [95\% CI $-16.2 \%$ to $-7.6 \%$ ]; DQ4-Q5 -5.2\% [95\% CI $-9.3 \%$ to $-1.1 \%])$.

\section{Discussion}

This paper examined the magnitude of inter-quintile differences in reported coverage for specific maternal care services among Filipino women. Quantified inter-quintile differences range from as low as less than $1 \%$ to as much as $60 \%$. On the other hand, there is a three-fold difference in coverage between the two lowest and the two highest adjacent quintiles across all maternal care services. With the exception of use of modern method of contraception and receipt of antenatal care, analysis carried out for this research showed that higher wealth groups almost always have greater access to maternal care services compared to those who belong to lower income groups. Even differences in coverage for maternal care services between the two highest quintiles amount to at most $10 \%$.

The data generated by this paper confirm gradients in socioeconomic status and health service access noted elsewhere. ${ }^{14}$ Such differences in access persist even among women who belong to the fourth and highest quintiles. Thus, it can be said that disparities in access to maternal care services, differing only in magnitude, exist among Filipino

\footnotetext{
${ }^{c}$ Skilled birth attendants include physicians, nurses and midwives. ${ }^{17}$
}

women across the economic spectrum. Furthermore, the existence of these differences despite the presence of government interventions to reform the health system to ensure greater access to health services at both the primary and specialized care levels ${ }^{4,18,19}$ serve to highlight the inadequacy of such measures to reduce inequities that are "systemic, socially produced, and unfair."11

To the author's knowledge, this is the first paper that measured the gap, or difference, in access to maternal care services among Filipino women. One limitation of the current paper is its reliance on summary statistics contained in the published technical report of the most recent demographic and health survey in the Philippines. A second limitation is its use of data that may be subject to information bias and selection bias, which may off-set by the large sample size attained for the survey through stratified two-stage sampling design; extensive pre-testing of questionnaire; and training of data enumerators. These limitations notwithstanding, the accuracy of point and interval estimates for inter-quintile differences in access to maternal care services presented in this paper is driven by the robustness of the source data used in the analysis.

Future research must determine whether inter-quintile differences in access to maternal care services has changed over the past decades, a more strategic information that will drive policy and practice considering that we have not been lacking in well-intentioned government and private initiatives in the past decades. Likewise, gaps in access to other essential health interventions, such as child care, need to be examined as well. Use of primary data for such future undertakings is ideal.

\section{Conclusion}

Gradients in access to selected maternal care services exist among Filipino women who belong to different wealth quintiles. The call for stakeholders, therefore, is to intensify efforts to narrow such gaps because, within and across communities, we affirm that no women "should die in the course of the normal process of reproduction" and no families must suffer the devastating consequences of such an occurrence. $^{20}$

\section{References}

1. World Bank. Country and Lending Groups [Online]. 2015 [cited 2015 Apr]. Available from http://data.worldbank.org/ about/country-and-lending-groups.

2. World Health Organization. WHO Countries: Philippines [Online]. 2015 [cited 2015 Apr]. Available from http://www.who.int/countries/phl/en/.

3. United Nations. Millennium Development Goal 5: Improve Maternal Health [Online]. 2015 [cited 2015 Apr]. Available from http://www.un.org/millenniumgoals/maternal.shtml.

4. 2011-2016 National Objectives for Health, Health Sector Reform Agenda Monographs. Manila: Department of Health; 2011. DOH HSRA Monograph No. 12. 
5. Trends in maternal mortality: 1990 to 2013. Estimates by WHO, UNICEF, UNFPA, The World Bank and the United Nations Population Division. Geneva: World Health Organization; 2014.

6. Philippine Statistics Authority. MDG Watch: Statistics at a glance of the Philippines' Progress based on the MDG indicators [Online]. 2015 [cited 2015 Apr]. Available from http://www.nscb.gov.ph/stats/mdg/mdg_watch.asp.

7. PMNCH. A Global Review of the Key Interventions Related to Reproductive, Maternal, Newborn and Child Health (RMNCH). Geneva: The Partnership for Maternal, Newborn, \& Child Health; 2011.

8. Implementing health reforms for rapid reduction of maternal and neonatal mortality, DOH Administrative Order No. 20080029, 09 Sep 2008.

9. Whitehead M. The concepts and principles equity and health. Copenhagen: WHO Regional Office for Europe; 1991.

10. Carter-Pokras O, Baquet C. What is a "health disparity"? Public Health Rep. 2002; 117(5):426-34.

11. Whitehead M, Dahlgren G. Concepts and principles for tackling social inequities in health: Levelling up Part 1 [Online]. 2006 [cited 2015 Apr]. Available from http://www. euro.who.int/_data/assets/pdf_file/0010/74737/E89383.pdf.

12. UNFPA. Maternal mortality update 2002: a focus on emergency obstetric care. New York: United Nations Population Fund; 2003.
13. Kiwanuka SN, Ekirapa EK, Peterson S, et al. Access to and utilization of health services for the poor in Uganda: a systematic review of available evidence. Trans R Soc Trop Med Hyg. 2008; 102(11):1067-74.

14. Benova L, Campbell OM, Ploubidis GB. Socio-economic gradients in maternal and child health-seeking behaviors in Egypt: systematic literature review and evidence synthesis. PLoS One. 2014; 9(3):e93032.

15. Barros AJ, Ronsmans C, Axelson $\mathrm{H}$, et al. Equity in maternal, newborn, and child health interventions in Countdown to 2015: a retrospective review of survey data from 54 countries. Lancet. 2012; 379(9822):1225-33.

16. The Aquino Health Agenda: Achieving Universal Health Care for all Filipinos, DOH Administrative Order No. 2010-0036, 16 Dec 2010.

17. Philippine Statistics Authority and ICF International. Philippines National Demographic and Health Survey 2013. Manila, Philippines and Maryland, USA: PSA and IFC International; 2014.

18. Health Sector Reform Agenda Philippines, 1999-2004, Health Sector Reform Agenda Monographs. Manila: Department of Health; 1999. DOH HSRA Monograph No. 2.

19. National Objectives for Health 2005-2010. Manila: Department of Health; 2005.

20. WHO. The word health report 2005: make every mother and child count. Geneva: World Health Organization; 2005. 